\title{
Response to Schwerla
}

\author{
Paul Posadzki • Edzard Ernst
}

Received: 31 July 2012 / Accepted: 9 August 2012 /Published online: 24 August 2012

(C) Clinical Rheumatology 2012

Sir,

The letter by Schwerla [1] deserves a brief comment. We did conduct electronic searches in Google Scholar, ISI Web of Knowledge, The Journal of the American Osteopathic Association, among others. Yet, we did not locate the website mentioned by Schwerla. Interestingly, neither did Licciardone [2] whose review Schwerla seems to hold in such high regard. It is clearly impossible for authors of systematic reviews to search thousands of websites to retrieve studies that usually are not peer reviewed and probably of poor quality. We also reject the allegation that we have not invited others to contribute further trials; the European meeting mentioned by Schwerla is unlikely to host more than a fraction of leading experts in osteopathy which, after all, is largely a North American field. Considering these facts, we are confident that our overall findings are correct [3] and hope that independent organisations such as the Cochrane Collaboration might replicate them. This, in our view, would be more valuable than the wishful thinking of interested parties.

It has recently been calculated that osteopaths (and chiropractors) are more likely to publish low-quality systematic reviews arriving at positive conclusions, and this trend is statistically significant [4]. Other researchers found insufficient evidence to support the effectiveness and biological plausibility of cranial osteopathy and craniosacral therapy $[5,6]$. To conclude, until independently replicated trials show that osteopaths generate clinically relevant improvements, researchers will remain sceptical.

Disclosures None.

\section{References}

1. Schwerla F (2012) Osteopathy for musculoskeletal pain: a systematic review. Clin Rheumatol 31(1):197-198

2. Licciardone JC, Brimhall AK, King LN (2005) Osteopathic manipulative treatment for low back pain: a systematic review and metaanalysis of randomized controlled trials. BMC Musculoskelet Disord $6: 43$

3. Posadzki P, Ernst E (2011) Osteopathy for musculoskeletal pain patients: a systematic review of randomized controlled trials. Clin Rheumatol 30(2):285-291

4. Posadzki P (2012) Is spinal manipulation effective for pain? An overview of systematic reviews. Pain Med 13(6):754-761

5. Hartman SE (2006) Cranial osteopathy: its fate seems clear. Chiropr Osteopat 14:10

6. Green C, Martin CW, Bassett K, Kazanjian A (1999) A systematic review of craniosacral therapy: biological plausibility, assessment reliability and clinical effectiveness. Complement Ther Med 7 (4):201-207
P. Posadzki $(\bowtie) \cdot$ E. Ernst

Complementary Medicine, University of Exeter,

Veysey Building, Salmon Pool Lane, EX2 4SG,

Exeter, UK

e-mail: Paul.Posadzki@pcmd.ac.uk 